\title{
Tadaluring Microteaching Learning Model (TMLM): Designing, Developing and Field Testing
}

\author{
Arifmiboy \\ IAIN Bukittinggi, Indonesia \\ arifmiboy@yahoo.co.id \\ Jamaris Jamna \\ Universitas Negeri Padang, Indonesia \\ jamaris.jamma@gmail.com
}

\author{
Mega Iswari \\ Universitas Negeri Padang, Indonesia \\ mega_iswari@yahoo.com \\ Agustina \\ Universitas Negeri Padang, Indonesia \\ agustina@gmail.com
}

\begin{abstract}
As a certified professional, teacher forms indispensable roles in achieving the learning objectives. The complexity of teacher's profession decidedly requires the teacher to master a number of competencies and skills. One of them is to master the basic teaching skills. Realizing the complexities of the teacher's profession and the requirement of teacher's profession, LPTK -Faculty of Teacher Training and Education- which produces professional teacher, requires enhancing the teacher's quality and creativity through pre-service teaching and training. Microteaching is one of the efforts to prepare the candidate for a professional teacher in higher education. The growth of a number of students being served with the availability of micro teaching laboratories is, however, disproportionate. Consequently, the problems faced are the time management, the laboratory utilization, the availability of sufficient microteaching infrastructures as well as the implementation of micro teaching itself. One of the ways to solve the problems is to develop a microteaching model adapting the force driving sophisticated ICT named TADALURING Microteaching Learning Model (TMLM). The Instructional Systems Design (ISD) made use of developing the model is Borg and Gall procedures. The cyclical phases of conducting the research were preliminary research, development, field-testing, and dissemination. The research finding indicates that the trial-tested model is stated valid, practical, and effective. The TADALURING Microteaching Learning Model (TMLM) is essentially accentuated on a face-to-face classroom, online and offline practices.
\end{abstract}

Keywords: tadaluring, microteaching

\section{INTRODUCTION}

The International surveys' results reported that quality of Indonesian education still extremely declines. The 1997 to 2007 World Competitiveness Year Book's survey reported that of the 47 countries surveyed, Indonesia ranked $39^{\text {th }}$ in 1997 and $46^{\text {th }}$ in 1999. Then in 2002, of 49 countries surveyed, Indonesia ranked $47^{\text {th }}$ and in 2007, of the 55 countries surveyed, it still ranked $53^{\text {rd }}$ [1]. Similarly, in 2005, A Global Monitoring Report released by UN agency, UNESCO, Indonesia ranked $10^{\text {th }}$ among 14 developing Asia Pacific's countries [2]. Another international survey, The United Nations Development Program (UNDP) reported that the Indonesian's Human Resource Quality ranked $109^{\text {th }}$ out of 177 countries in the world [3]. Meanwhile, The Political and Economic Risk (PERC) Consultancy Agency in Hongkong informed that the quality of education in Indonesia still extremely declines among 12 Asian countries studied. This indicated that the quality of education in Indonesia drew level with Honduras and Nigeria although it is better than the Vietnam.

At the praxis level, the educational problems designate the obstacles to realistically achieving the goals of national education as legally mandated in the Law No. 20 of 2003 on the National Education System. The declining quality of Indonesian Human Resources (HR) becomes one of the real causes of the obstacles. The decline can be analyzed from several macro indicators, among others, are the 2008 to 2009 Global Competitiveness Report from the World Economic Forum in Martin stating that Indonesia ranked $55^{\text {th }}$ out of 134 countries in terms of the achievement of Competitiveness Index (CI). Subsequently, the United Nations for Development Program in Human Development's 2007/2008 research results reported that Indonesia ranked at the $107^{\text {th }}$ of 155 countries in terms of Human Development Index's (HDI) achievement [4].

The declining quality of Indonesian education had been clearly elucidated by the Study Program for International Student Assessment (PISA) in 2003. PISA reported that, for Science and Mathematics literacy, 15-year-olds ranked $38^{\text {th }}$ out of 40 participating countries and for reading literacy, Indonesian students ranked 39th. In 2006, the reading literacy achievement of Indonesian students ranked 48 th out of 56 countries while mathematical literacy ranked 50th out of 57 countries, and science literacy ranked 50th of 57 countries. Furthermore, in 2006, the Progress in International Reading Literacy Study's (PIRLS) research report on the grade 4 elementary school children's reading literacy worldwide under the coordination of The International Association for the Evaluation of Educational Achievement (IEA) in 45 countries/states, both from developed countries and developing countries, found that Indonesian students ranked $41^{\text {st }}$ out of 45 participating countries [5].

Similarly, Balitbang's Data indicated that quality of Indonesian education extremely devastated. The data explained that 8 of 146,052 elementary schools nationwide which has been internationally recognized as The Primary Years Program (PYP). Similarly, 8 of 20,918 Indonesian Junior High Schools which has been internationally recognized as The Middle Years Program (MYP) and lastly, 7 out of 8,036 Senior High Schools which have been 
internationally recognized as The Diploma Program (DP). The results of the Teacher Competency Test (UKG) held by the Ministry of Education and Culture in November 2015 were still beneath the expected standards. As disclosed by the former Minister of Education and Culture, Mr. Anis Baswedan, PhD, "the average national UKG's score exceptionally declined. The average of national UKG's score was 53.02, whereas the government targeted the average score was at 55. In addition, the average professional competence's score was 54.77 while the pedagogic competence's score was 48.94" [6].

In response to the aforementioned conditions, it requires central government and stakeholders' efforts to improve the quality and competence of Indonesian teachers. These efforts and improvements will automatically assist the achievement and accomplishment of Indonesian education. The process of enhancing Indonesian teachers' professionalism must be early begun when the prospective teachers are studying in university (pre-service). As prospective teachers, the students should possess, experience, and master a variety of courses related to pedagogic competence such as learning planning, learning strategies, instructional media, curriculum development, educational psychology, and learning evaluation. All of these courses will provide pieces of fundamental educational knowledge to prospective teachers in the context of enhancing their pedagogic competence. One of the efforts that can be undertaken to develop the teachers' pedagogic competence is the process of educational training that is packaged in a micro teaching course. Theoretically, Dwight Allen clearly explicated that the primary goal of micro learning is to separately provide the real learning experiences, practices and some indispensable teaching skills to the prospective teachers. They are expected to develop their teaching skills prior to teaching at the real classroom setting [7].

Preliminary studies were undertaken at three Faculties of Teacher Training and Education at IAIN Bukittinggi, IAIN Batusangkar, and IAIN Imam Bonjol Padang to investigate the real conditions of microteaching's soft and hard infrastructures. The results indicated that there were a number of critical issues with regard to the microteaching learning and its soft and hard infrastructures. The problems encountered included the availability of adequate micro teaching laboratories, limited lecture rooms, laboratory utilization, time management, a limited number of training opportunities, and declined mastery of basic teaching skills by prospective teachers. On the other hand, the ICT has rapidly developed. The range of the developed digital communication devices is mobile phone, laptop, tablet PC, i-pad and so forth. These electronic devices certainly have a great impact on human life including in education field. The changes in digital devices can be seen from the people who initially only use letters and telegram as a communication means developed into using mobile phones, e-mail, Skype, WhatsApp and so forth.
The development of the sophisticated information technology in the field of education opens an access or provides opportunities to undertake the long distance education using the internet media to connect the students with the lecturers, access college schedule, check finances, and send the task files and or documents given by teachers and so on. Everything can be easily done online. Taking into account of the problems faced in microteaching learning along with the development of ICT's facilities, there is a call for developing a Model of Microteaching Learning adopting the today's technological developments as a realistic solution to the problems.

\section{METHODS}

The Borg and Gall's Instructional Systems Design forms the 4 pieces most important cycles in developing the TADALURING model. The stages are preliminary research and information gathering, planning, initial product development, initial product testing, major product revisions, major product trials, product operational revisions, operational product trials, final product revisions, And dissemination and implementation [1]. In general, in developing the model, TADALURING, it has four main stages. They are: stage 1 preliminary research; stage 2 model development; stage 3 field test or model validation; and stage 4 dissemination. For more details, the stages are described as follows.

The preliminary study was packed into the form of survey research, the data collected were closed questionnaires that had been designed and validated beforehand. Questionnaires were distributed to 90 students who had attended microteaching lectures in the 2016/2017 academic year at three college teachers under the supervision of the Directorate of Islamic Higher Education (Diktis) in West Sumatra province, namely IAIN Bukittinggi, IAIN Batusangkar, and IAIN Imam Bonjol Padang. The accidental sampling was used as a technique of getting any particular samples.

The stages of developing the model were the combination of a planning along with developing the preliminary form of the product. The research activities carried out included the definition of skills studied, the formulation of learning objectives, determining the sequence of learning (syntax), and a small-scale feasibility testing. Then, the researcher developed a draft of a product that included the presentation of learning materials, administering or organizing a model book or handbook as well as evaluation instruments. The result of this activity was to get the draft design model ready in a trial.

Preliminary research results, relevant research, and literature study served as the basis for the preparation of microteaching model TADALURING. The stages of learning model development included some of the following activities.

1. Drafting and or composing the design of the model. The basic drafting and or composing of this design used was the preliminary study, the foundation of learning theories, the theory of 
model development, and the feasibility of its implementation.

2. Experts' validation and practitioners. To validate the design of the developed model was undertaken through experts' judgments. The experts who had been involved were Prof. Dr. Harris Effendi Thahar, M. Pd as a linguist, Dr Jsrial, M. Pd as the design expert, Dr H. Darul Ilmi as a material expert, Dr Asrul Huda, M. Kom as a media and ICT's expert, and Dr Ir. Khairani, M. Pd as an evaluation and instrument's expert. The instruments used in conducting the feasibility test were the validation sheets for the experts. The validated components were language, developed model structure, teaching preparation, basic teaching skills, observation sheets, questionnaires, observation checklists, and interview guides. Every expert had provided insight and input regarding the design of the developed model. The inputs and suggestions had been used as a basis for the draft revisions of the designed model. More importantly, the researchers had used validation sheets which could shape the revision processes of the designed model. The result generated the hypothetical design that has been tested on subsequent activities.

3. Revising the draft of the designed model. The revised draft of the designed model referred to the suggestions and inputs on the desk evaluation comprised of the experts' validation sheets.

The field trial-testing consisted of three forms. They were a preliminary field test, main field test, and operational field test. Preliminary field tests were performed to obtain the valid theoretical validation. Meanwhile the main field tests were undertaken to obtain effective recognition used in achieving learning objectives, while operational field tests were carried out in order to gain practical recognition from the users. The products' field trial-tests were validly, effectively, and practically interpreted.

The developed TALALURING microteachinglearning model was validated by a number of experts in their respective fields (experts' validation). The expert validity was undertaken in order to obtain the theoretically, substantially, and methodologically experts' recognition. Experts in question are design, linguists, microteaching learning materials, and ICT media experts. Validated objects are instruments, model books, and learning tools. The resutl showed an average score of 3.72 and validly interpreted.

The effectiveness' test of product design (main field test) was meant to find out the effectiveness of the design of the developed product. The effectiveness test was undertaken in the form of quasi-experiment research with Non-Equivalent Group Design (Figure 1). The quasi-experiment design can be described as follows [5].

The research designs above comprised of two experimental groups, the two groups were given a pretest and then treated and the last was to provide a posttest class. The experiment was given to 24 students in the English Department of teacher training Faculty of
IAIN Bukittinggi the seventh semester of 2016/2017 academic year. Adapting to the research design model used, the researcher divided the samples into two groups comprising of 12 participants tailoring to the amount of set by the study programs for each study group in microteaching lectures. The sample used was accidental technique. Based on the pre-test and post, the gained avarage scores were 14. 10. Besides, the hyphothesis which suggested that the mean's score of the mastery of the basic teaching skills is higher then 80 , is accepted. The score of $t_{\text {obtain }}>t_{\text {table }}(2.065>$ 1.711).

\begin{tabular}{|c|c|c|c|}
\hline \multicolumn{4}{|c|}{ Nonequivalent Control Group Design } \\
\hline & $\mathrm{O}_{1}$ & $\mathrm{X}$ & $\mathrm{O}_{2}$ \\
\hline & $\mathrm{O}_{1}$ & $\mathrm{X}$ & $\mathrm{O}_{2}$ \\
\hline \multicolumn{4}{|c|}{ Note: } \\
\hline $\mathrm{X}$ & $=$ Treatment & & \\
\hline $\mathrm{O}_{1}$ & $=$ Pre-test & & \\
\hline $\mathrm{O}_{2}$ & $=$ Post-test & & \\
\hline
\end{tabular}

Figure 1

Experiment Design

The practicality's test involved three universities namely IAIN Bukittingi, IAIN Batusangkar, and UIN Imam Bonjol Padang. The number of lecturers involved was 15 people with different areas of expertise.

The procedures of undertaking the practicality' test were to ask for the experts' willingness, provided training on the use of learning models, and distribution of questionnaires about practicality. The respondents were selected based on several considerations that the s/he is microteaching lecturers, has the basic capability for operating ICT facilities, and are willing to apply the developed microteaching learning model. The result showed that an average score of 83,53 and effecftively interpreted.

Dissemination and implementation were the last part activities of developing the TADALURING microteaching learning model. Dissemination is a report on a product presented at a professional meeting (international conference/seminar) and or published in the indexed international journals. The publication of the indexed international journals forms the dissemination of this scientific idea.

The selection of trial-tested subjects, the researcher has used several criteria of having doctoral education qualification, mastering knowledge and skills in microteaching learning field for expert in microteaching, mastering knowledge and possessing experience in designing lesson for expert in instructional design, and mastering ICT knowledge and skill for experts' appraisal on ICT and language experts to validate languages.

The product effectiveness trial-test was undertaken through the quasi-experiment involving 24 students of the prospective teachers at the faculty of Teacher Training and Education of IAIN Bukittinggi in 2016/2016 academic year. Whereas the practicalities test, it involved 15 lecturers from three 
Islamic state universities in West Sumatra province namely IAIN Bukittinggi, IAIN Batusangkar, and UIN Imam Bonjol Padang.

In conjunction with the model and procedures of developing the TADALURING microteaching learning model, the quantitative data was obtained through the questionnaire about the implementation of microteaching, pre-test and post-test, interest in becoming teachers, lecturers' understanding of supervisors, student attitudes toward learning, and questionnaires on validity and practicality. Qualitative data obtained through interviews with some lecturers who teach courses microteaching and laboratory managers.

The data were colleced by using valid and reliability questioner, validation sheets, observation sheets, and interview guides. Quantitative data were analyzed using descriptive and inferential statistics. Descriptive statistics are used to test the validity and practicality of a product. While the effectiveness test using SPSS 20 software to test instruments' validity and reliability, normality and homogeneity test data, the difference test of one and two averages, score gained, factor analysis and determine interclass correlation (ICC).

\section{RESULT AND DISCUSSION}

The Tadaluring is the acronym of a face-toface, inside and outside the network. Tadaluring Microteaching Learning Model (TMLM) is a learning model that combines the forms of teaching practices in an integrated way using communication technology media. These combinations form the faceto-face classroom's practice, face-to-face Online's practice, and face-to-face offline's practice.

Tadaluring microteaching learning model is classified into a family behaviour modification model. In the behaviour modification models are also known a number of model namely; Contingency management model, self-control model, training model, stress reduction model, desensitization model, and assertiveness training model. From a number of various branches of the model, the microteaching Tadaluring learning model includes training model. The construction of the micro teaching course flow is illustrated as follows.

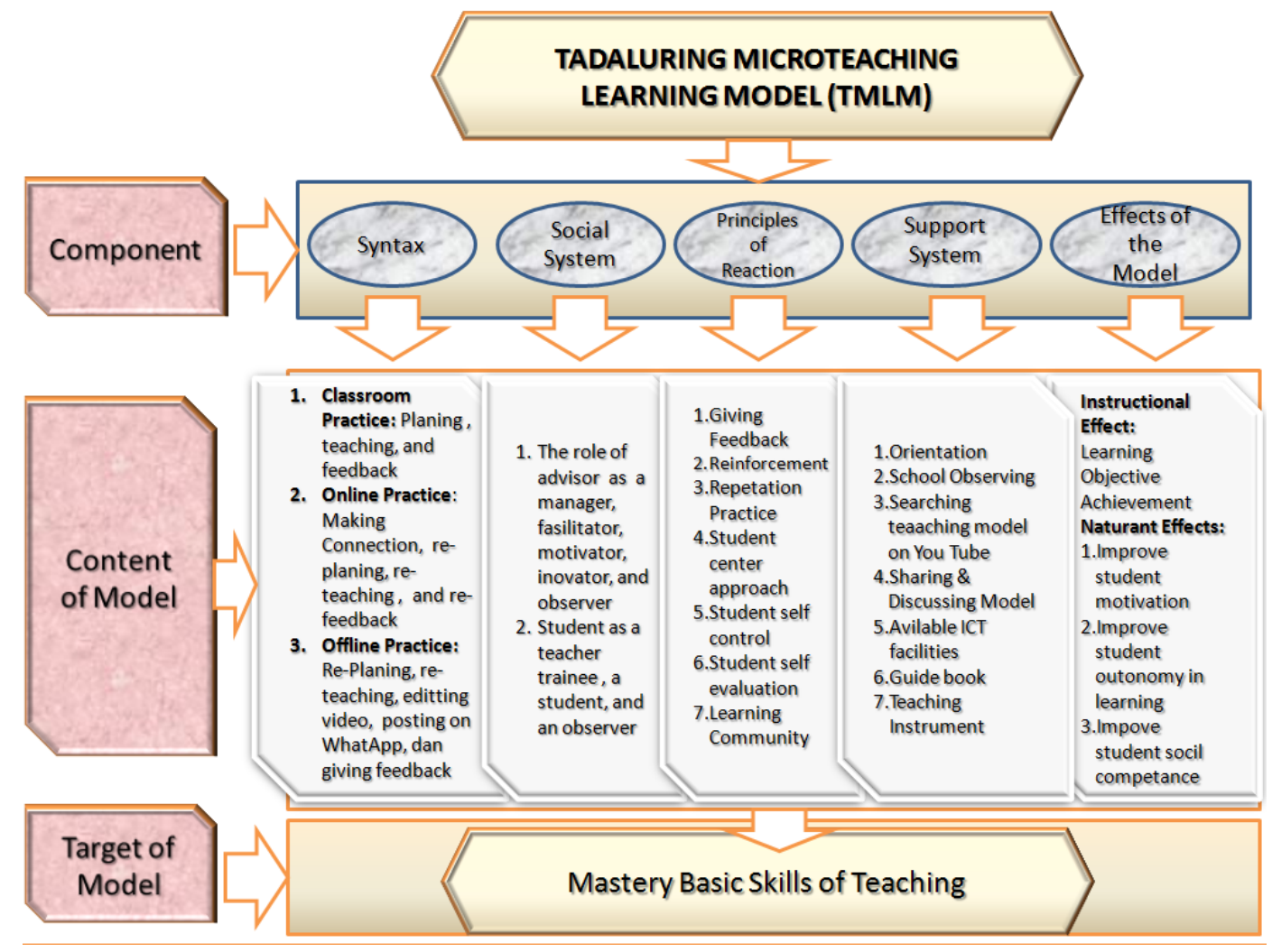

Figure 2

Tadaluring Microteaching Learning Model

Based on the above diagram, it can be understood that the Tadaluring microteachinglearning model is based on the syntax components, social systems, principles of reaction, support system, and effect of the model. The details are elucidated as follows. The classroom practice is a teaching practice activity undertaken in the classroom directly attended by supervisors and trainees in microteaching learning.
The steps of teaching practice in the classroom are planning, teaching, and providing feedback. The planning activity is an activity in formulating the training strategy, such as determining the type of skills trained, determining the topic of discussion, method, learning approach, and the form of students' engagement and participants. 
The teaching practice is an activity demonstrating a range of basic teaching skills. The trainee immediately practices his/her teaching practise in front of the participants as students and supervisors. The teaching practices are conducted alternately in accordance with the schedule of appearances/performance that have been prepared and agreed upon beforehand. The training activities are partially carried out by each participant with duration of between 5 to 7 minutes on each basic skill.

Basic teaching skills that should be practised by microteaching participants are the skills of opening and closing learning, explaining, asking, variation, giving reinforcement, guiding small group discussions, and classroom management. These basic skills are first partially or partially trained. Each meeting is only one form of basic skill for all participants. This is done so that participants master the things that should be done on each of the basic skills trained.

After the participants have mastered a range of forms of basic teaching skills then followed by an integrated training. An integrated training is a form of training that combines all the basic teaching skills in a unit of training. In the integrated training's activities, participants must consider several components, namely micro plan, learning model, approach, strategy, method, and instructional media. Implementation of the integrated training is done in rotation with a duration of 25-30 minutes per participant. The integrated training describes a complete learning but is still in a reduced condition both in terms of the objectives to be achieved, the breadth of the material, as well as the time provided.

Practice activities in the classroom conducted as many as 12 times of meetings consisting of 7 times for partial practices and 5 times for the integrated practices. The time duration provided for each participant's practice on basic partial skill is 5-7 minutes and for 5-minute feedback. So the total time for each participant is approximately 12 minutes. While the practice in an integrated manner has a duration of 20-30 minutes per participant and 10 minutes to carry out reflection activities. Lecturers in the implementation of teaching exercises in the classroom equipped with a camera to record the training activities of participants, the recording can be used as a basis for providing feedback. This recording activity is important so that the participant can re-watch their performance and be aware of the forms of deficiencies or weaknesses that are still visible and can improve on the next performance.

Feedback is given by participants and supervisors at every performance. Giving feedback can be done directly or sending it to the WhatsApp group. The importance of embracing feedback is to allow the students or trainees understand what aspects required to enhance. In this situation, the supervisors serve as a motivator to reinforce and motivate students in spite of criticising.

Schedule of training activities in the classroom is adjusted to the schedule set by the administration staff tailoring to the number of credit courses. The number of credits for microteaching classes in the class is set by 2 credits courses or is equivalent to 100 minutes per week with the number of participants in each study group of 12 to 15 people.

\section{Online Practice}

In-class practice activities continued with the online practice. Online practice is a practice activity carried out online with the help of means of communication over the Internet using Skype facility. With Skype facility allows supervisor and all participants can interact directly at the same time and different places. All participants and supervisors meet directly on their computer screens. Each participant and lecturer can see and greet each other.

Online practice is done by making the connection, re-planning, reteaching, and re-feedback. Making connections is an attempt to connect every participant to a network within a group of video calls using Skype. Each participant has been connected to the internet network and has been in front of a laptop's screen used at an agreed time. Supervisors make one call to the group, automatically all participants in the group will be called and connected. For participants who are late to activate the device then to join, s/he needs to make calls to the group. The calls will be connected with the other participants if it has been accepted by the supervisor.

The second step is re-planning. In the connected condition, the supervisor asks and gives 57 minutes to the participants who will appear at the meeting to strategize or prepare everything needed in the training session. The scope of the plan is to determine the type of skills to be trained, topics, and exercise scenarios. It is important that participants understand and behave accordingly.

After the planning is over, the participants teach (re-teach) like a teacher who teaches in the classroom. Each participant re-assumes previously trained skill in the classroom and expected not to repeat the same mistakes that have been previously commented. For participants who appear standing approximately 2 meters from the position of the camera is placed and can walk closer to the camera when needed, while other participants pay attention in front of the device as follow a lesson conducted teacher in front of the class. Each microteaching participant either acting as a student, teacher, or mentor can greet or ask each other during the online training process.

The activity ends with providing feedback. Feedback can be done in two ways namely verbally when online and in writing on WhatsApp group. Feedback is packed into the forms of suggestions, criticism, and appreciation. Suggestions, criticism, and appreciation can improve the next performance of the students and increase the motivation of participants in practising.

Offline practice is a follow-up activity of online classroom practice. Offline practice is the practice of teaching activities conducted independently by involving several students or colleagues as a media in the project. Offline practice 
places emphasis on maximizing opportunities for practice. Each participant recorded his or her training activities independently of both basic and integrated teaching basic teaching training.

Offline practice is done by several steps, namely planning, assigning students, preparing recording tools, teaching practice, editing, posting video recording, and providing feedback. Planning is organized like a classroom exercise and online. Setting the type of skill to be trained, setting topics for discussion, and preparing for everything needed at the time of the pre-school. The form of preparation of teaching on the exercise activity is partially different from the practice in an integrated manner. Learning planning in integrated skills training describes a complete learning and involves a number of planning elements. Elements of learning referred to the objectives and indicators of learning, preliminary activities, core activities illustrating Learning models, approaches, strategies, methods, media, learning materials, and closing activities.

Offline practice is part of the microteaching practice that is done independently by each participant outside the class hours. This activity aims to multiple opportunities to practice basic teaching skills both partially and integrated. Offline practice is recorded by the student as a lecture's bill and submitted to the designated class leader (chairperson) each week. In offline practice, each participant is required to record his or her own training activities independently 5 (five) times on each basic teaching skills that have been partially trained in the class with a duration of 5-7 minutes each. Besides the partial skill recording is also requested 5 times in an integrated video duration of 20-30 minutes.

The offline practice involves a number of students as a medium in practice. To practice it, offline microteaching participants find themselves a number of students (4-8 people) who are at his residence. Students should be students in real condition who are studying at the SLPT or SLTA level. But if it can not be done then the other option is a lower-level student or a friend in microteaching learning. This offline practice can be done anywhere, like in a boarding house, at home, in a field, in a particular place and in a classroom. There are a number of electronic devices that can be used in recording practice activities such as hand cam, digital camera, webcam, and handphone camera. In recording activities, one needs to pay attention to some conditions such as focus shooting, lighting, and camera placement.

Before each recording video is posted and submitted to the supervising lecturer for grading, participants can first edit the videos they recorded on their own using the Camtasia Studio program. The activity is part of the self-evaluation process because by doing the editing process by themselves, the students have done the evaluation and realized the forms of mistakes or deficiencies they have done during learning. Assuming that if someone knows his mistakes, s/he unlikely will not repeat the same mistakes in the future. Videos that have been edited and considered interesting and have high quality are then posted to the WhatsApp group and soft copy submitted to the supervisor. Offline practice aims to provide widespread opportunities in practicing so that participants are fully trained in mastering the basic teaching skills.

\section{Social System}

In the Tadaluring microteaching learning model, the role of the student is more dominant than the supervisor. The role that students play in microteaching learning is as a practising teacher, as a student in other conditions, and as an observer or evaluator. Students as teachers in microteaching learning when they practice mastering the basic skills of teaching, they will act as real teachers, starting from planning lessons, strategizing, choosing media, methods, implementing learning to carry out the evaluation. On the other hand, the students will also act as students. Students as microteaching participants will behave and act like a student, ask questions, carry out teacher commands, answer teacher questions, hear explanations, and write various materials presented in accordance with the conditions that other participants who are practising as teachers.

Furthermore, the student as a microteaching participant is an observer as well as an assessment team. As an observer, the student will observe every gesture and learning process conducted by his colleague and then provides an assessment through the observation sheet prepared by participants who perform the practice. Even students will also provide comments in the form of suggestions and criticisms that are constructive in order to improve the appearance for the next exercise. In Tadaluring microteaching-learning model, supervisors have a very important role in realizing learning goals. The supervisor is the director and the actor in charge. The role of lecturers is a demonstrator, facilitator, motivator, innovator, inspiratory and evaluator/observer.

As a demonstrator, supervisors play a role in demonstrating everything that is didactically taught. The behaviour of supervisors to demonstrate the basic skills of teaching so that students can understand the various forms of activities that must be done on each of the basic teaching skills trained. Attempts to demonstrate basic teaching skills can also be done through the media presenting the video footage of basic forms of teaching skills. The lecturers as facilitators serve as to facilitate the students to practice optimally so that they comprehensively master a range of basic teaching skills trained. Faculty as a facilitator means that lecturers should be able to provide freedom for students in developing their potential and trying to foster student self-reliance.

The success of microteaching learning is also inseparable from the motivation owned by the students, the highest the motivation to practice, the more the students master the skills trained. Lecturer also plays an important role as motivators in learning, which plays a role in stimulating the students to practice as optimally as possible. To motivate the 
students, the advisors can interfere with the factors that can influence the motivation, by eliminating the feeling of anxiety, developing self-esteem appear in front of the students, changing the student mindset when given comments and inputs, and raising expectations.

Furthermore, as an innovator, it means that the knowledge conveyed to the students must always be up to date, in the sense of being able to absorb various forms of renewal in the world of education, such as curriculum development, innovative learning models, mastering the development of science and technology, democratic attitude, Students to be creative in implementing learning. Often, in microteaching learning students have not had ideas or inspiration for various forms of learning experience that will be presented at the time of teaching practice. Students have mastered the various materials that will be communicated in the lesson but have not had the right way, strategy, media, and model used to communicate the ideas to the learners to the students. Supervisors play an important role in providing ideas, especially in determining the model of learning, approach, methods, media, and various learning experiences that will be presented by students in a learning or training activities.

In Tadaluring microteaching-learning, there are a number of reaction of principles namely repetition and improvement, giving immediate feedback either directly or indirectly, giving both verbal and nonverbal reinforcement, providing motivation, studentcentred learning, self-evaluation, and learning Independent. The mastery of basic teaching skills is not easy. It takes a long time and process. A skill will be completely mastered if the skill is often done or repeated. This is in accordance with Thorndike's opinion known as the law of practice (low of exercise). In microteaching learning, repetitive exercise process is a very important and decisive thing to achieve the learning objectives. The repetitive exercise should be followed by corrective action. This means that there must be an improvement to the performance and skills trained.

In practice, students always have shortcomings and weaknesses. Therefore, the lecturers and students as participants must provide feedback in relation to the exercise/training activities undertaken. Feedback is undertaken in the form of providing comments, suggestions, criticisms, or judgments. Giving feedback can be done directly and indirectly or instantly done verbally at the end of the exercise/training activity for each participant. Suggestions, criticisms, moments carried out based on the direct result by participants and lecturers. In giving feedback directly should rewind or play back the recording of the performance by each participant. Therefore, suggestions, criticisms, and comments are more realistic and concrete.

The indirect feedback is provided through the supervisors or lecturers. Firstly, in writing, in order to correct the recording done independently by each participant on each basic skill either partially or integrated, the supervisor gives the comment, suggestion, assessment and criticism in writing on the observation sheet. In the suggestion column, the supervisor mentions the minutes and seconds of the error. Secondly, feedback is also provided through the WhatsApp group. The supervisor will comment on and provide written advice through WhatsApp group facilities. Giving feedback through WhatsApp begins with the activities of posting video training conducted by every participant, then supervisor lecturers and participants will provide comments, suggestions, and criticism for improvement. Giving feedback is important to know the forms of mistakes made to be improved, on the other hand, it is also to find out certain parts of the student appearance that needs to be maintained in the next performance.

In relation to the feedback and performance of the students' training, the supervisor is required to provide reinforcement. Reinforcement can be done verbally or nonverbally. Verbally is by using words that can please the hearts of students who practice, nonverbal can be treated with hand movements (applause), awarding something, and other forms of activity. Reinforcement aims at motivating students are to actively and diligently practice and complete in timely self-assigned tasks. When students feel satisfied with their performance and comments received from their supervisors and colleagues, the motivation affects their external and internal motivation. On the contrary, if their performance and the comments received from their supervisors and colleagues greatly displease them, it will lower and devastate their motivation to practice. This is in accordance with Thorndike's theory known as the law of effect (low of effect).

Tadaluring microteaching-learning model can be done effectively if it meets a number of activities and the availability of other supporting facilities are orientation, school observing, searching teaching model on You Tube, sharing and discussing, available ICT facilities, guide book, and teaching instrument. Orientation is an early activity in the microteaching learning process which consists of several key elements of delivering lecture contracts, group organizing, prerequisite capability analysis, simple training on the use of ICT tools to be used, reviewing materials on writing lesson plans, and the types of basic teaching skills Along with their respective indicators.

The lecture contract is concerned with the understanding of the microteaching course, the objectives achieved, the form of the course, the form of the course bill, the ICT devices used, the schedules, the assessment forms along with the indicators, and the course references. This is important to avoid misunderstanding of students to microteaching lectures. Group organizing is a grouping activity of students into 3 or 4 groups, each group consisting of 4 to 5 people. Selection of group members can be done randomly. The purpose of group formation is to facilitate the implementation of various activities in microteaching learning.

The analysis of students' understanding of basic teaching skills that must be mastered, the availability of ICT infrastructure and the ability to 
operate ICT infrastructure is the next orientation activities. Data collection in the analysis activities can be done through the questionnaire. The result of data processing is then used as the basis for the next strategy, if the majority of students have understood the various basic teaching skills that have been explained then the lecturer does not need to give more reviews. In the case of ICT facilities and infrastructure, if microteaching participants do not have the ability to use them, especially the use of camera, Camtasia Studio, You Tube, and Skype, it is necessary to do a simple training.

School observing is a visit to schools where teaching practice is done by each member of a group of microteaching participants in order to obtain some data related to the learning process at school. Implementation of school observation begun by preparing letters to the schools that will be visited. Subsequently, students prepare the observation sheet that has been prepared by the supervisor. Observations were conducted in groups of 4 or 5 persons according to previous group divisions.

The data required is collected to school by a microteaching student. The data are about learning media such as lesson plans' format, syllabus, annual program, semester program, teaching materials, student handbook, and teacher handbook. Subsequently, learning approaches and curriculum used, tools/devices and learning media available, student activities inside and outside the classroom, learning facilities and infrastructure at school, learning conditions inside and outside the classroom, as well as the dynamics of school life.

The data of school observation will be used as a reference and the basis for developing learning strategy in the teaching training activity at a later date. This is important to undertake to avoid the gap between the conditions that occur at schools where the teaching practice and the condition of the exercise in the classroom or microteaching lectures.

\section{Searching Teaching Model on You Tube}

Searching model is one example of the model or mastery model of various ideal basic teaching. Examples of such activities can be done by visiting the site of www.youtube.com on the internet network. Various models of keyword mastery video will appear when the keyword from each keyword is written in the search column.

On the YouTube network, there are a number of videos that present teaching models or basic teaching skills mastery models. The video presents a considerable learning situation with different teaching qualities, so students need to select videos that meet the criteria or indicators on each basic teaching skill. Selection of video as a model can be done through discussions with colleagues.

The purpose of the searching model is to provide experience and examples of basic mastery of basic teaching skills. It is expected that after students watch various interesting videos, they will try to imitate the existing behaviour. Thus students have guidelines that can lead them to behave at least like the video shows.

After downloading a variety of model of basic teaching skills' mastery, the microteaching participants are asked to share and discuss them. Sharing activity is done by using flash disk or send the videos by e-mail, but it should be better done by way of the flash disk then discuss them. Discussion activities conducted in order to evaluate the models that can later be used as a guide and examples of teaching training/exercise activities. A good model certainly has indicators that exist on every basic teaching skill.

The sharing and discussion activities were conducted in groups of students. The interesting points of each model video are recorded by the participants in their booklet and reported to the supervisor. This sharing and discussion activities are conducted with the aim of the participants to really understand the various activities or behaviours that should be raised on every basic teaching skill as well as obtain various interesting tricks in teaching practice activities. The sharing and discussion activities can be done by students outside the scheduled hours of lectures.

The ICT-based microteaching learning can be done effectively if all participants and lecturers have adequate ICT facilities. The ICT facilities are a computer, web cam, and internet network with minimal speed especially for online practice using Skype. The bandwidth required by Skype depends on the type of call being made. The more groups of videos online at the same time the more bandwidth they need. For microteaching-learning with 12 videocall participants in a single call requires $8 \mathrm{Mbps} /$ $512 \mathrm{kbps}$.

The views, which can produce clear images in addition to the internet network speed, are also required a high-resolution webcam device. The limitations of the device resolution with the built-in webcam are often problematic constraints. In general, the built-in webcam has a resolution of about $352 \times$ $288,640 \times 480$ and $1 \mathrm{MP}$, so the resulting image is not good quality. To produce good image quality, it requires a webcam with $720 \mathrm{p}$ or $1080 \mathrm{p}$ resolution with an HD display that has a screen resolution of $1280 \times 720$ px with speeds up to 30 frames per second.

The implementation of Tadaluring microteaching-learning requires a manual that will be used as a reference in implementing learning. The instruction manual describes in detail of microteaching learning, namely, understanding, competency standard, purposes, characteristics, benefits, and microteaching learning procedures. The manual covers basic competencies and indicators of achievement of learning objectives, the preparation of the Lesson Plans, the basic teaching skills' forms of those participants should master as well as the mechanism of implementing the microteaching learning. The handbook is also completed with the format and assessment system done in teaching and or learning. 
Teaching Instruments

The implementation of Tadaluring microteaching learning model will be more effective if the supervisor is also equipped with learning tools and or media. Learning media are used as an operational reference for the implementation of learning. Learning tools contain a number of elements namely Syllabus, RPKPS, Effective Week Plan, and Lecture Unit Lectures.

The microteaching syllabus is designed and administered based on the competency standards achieved in learning. The elements of the syllabus comprise of the identity of the course, the description of the course, the desired competencies, the indicators of the achievement of competence, the learning resources, the scoring system. Thus, the syllabus is a general guideline for the implementation of microteaching learning which is an integral part of the supporting system of Tadaluring microteachinglearning model. Furthermore, the facilities which are required in implementing the Tadaluring microteaching-learning model is the Semester Learning Activity Plan (RPKPS) which comprises of the course descriptions, learning objectives, lesson plans, and weekly activity schedules in more detail during one semester. RPKPS serves as a guideline and controller of its course in implementing the learning for one semester.

The other sustaining facilities which are required in the Tadaluring microteaching-learning model are syllabus and SAP. The syllabus is a translation of the curriculum used. Syllabus and SAP contain the synopsis of the course, competency, of course, competency indicator, topic/sub topic, and reference. To effectively implement the curriculum, syllabus and SAP should be well developed into a lecture course (SAP). SAP contains components of competency standards, basic competencies, competency indicators, lecture materials and descriptions, learning experiences (learning strategies), instructional media, assessment systems, and references. SAP is also a projection of activities or activities to be performed by supervisors in lecturing.

Tadaluring Microteaching Learning Model provides two forms of Effects. The first is direct effect. The Tadaluring Microteaching Learning Model is able to achieve the goal of microteaching learning itself. The students of microteaching participants are able to master a mixture of basic teaching skills trained. Second is indirect effect. The indirect effects can improve student's learning motivation, student's learning independence, and students' social competence such as cooperation, mutual respect, mutual help, and reminds well behaved.

Conceptually, the "microteaching" stems from two words, namely micro and teaching. Micro means small, limited, and narrow, while teaching means educating or teaching. Allen and Ryan in Lakshmi explicate that microteaching as a scaled down teaching encounter, scale down in term of class size, lesson, length, and teaching complexity [8]. Whereas
Allen point out that "microteaching as a system of controlled practice that make it possible to concentrate on specific teaching skills and to practice teaching under controlled conditions" [9]. Singh states that microteaching is a training technique, which requires pupil teachers to teach a single concept, using specified teaching skills to a small number of pupils in a short period of time [10].

Cooper and Hillary affirm that microteaching forms a teaching situation undertaken in very limited time i.e., for 5-20 minutes with 3 to 10 students [11]. Furthermore, Mc. Laughlin and Moulton describe microteaching is a performance training method designed to isolate the component part of teaching process, so that the trainee can master each component one by one in a simplified teaching situation. Lakshmi adds, microteaching is a scaleddown teaching encounter' in which a teacher teaches a small unit to a group of 5 to 10 pupils [11]. Barmawi highlights that the difference between microteaching and teaching in terms of the number of students. In microteaching class, it comprises of 5 to 10 students whereas in teaching, it includes 30 to 40 students. In conclusion, microteaching is an extremely controlled teaching training to master certain basic teaching skills in a minimised learning condition in terms of time, materials, skills, and a number of students [11].

Dwight Allen explains that the purpose of microteaching for prospective teachers is to: 1) provide real teaching experience and practice a number of basic teaching skills, 2) the prospective teachers can develop their teaching skills ahead of entering the field; and 3) provide a variety of basic teaching skills. For teachers themselves, it refreshes educational programs, and expands teaching experience individually to develop professionalism, and build up an open attitude for teachers to innovation [11].

The main characteristic of microteaching is minimization or simplification. The word refers to the amount of time, amount of teaching materials, number of skills, and number of students. Sharma in Lakshmi identifies the characteristic of microteaching learning: (1) real teaching, microteaching is real teaching. however, it focuses of developing teaching starts; (2) scaled down teaching, the following out line is characteristic of scale down teaching: scaling down the class size of five to ten pupils, scaling down the duration of period of five to ten minutes, scaling down the size of topic, and scaling down the teaching skill; (3) individualized device, it is a highly individualized training device; (4) providing feedback, it provides the feedback for trainee's performance; and (5) device for preparing teachers, it is a device to prepare effective teachers [10].

Allen and Ryan in Sukirman identify the fundamental characteristic of microteaching: (1) microteaching is real teaching; (2) microteaching lessons is the complexities of normal classroom teaching; (3) microteaching focuses on training for the accomplishment of specific tasks; (4) microteaching allows for the increased control of 
practice; and (5) microteaching greatly expands the normal knowledge of results of feedback dimension in teaching [10].

Referring to the experts' points of view, the writer concludes that the microteaching is learning processes whose exceptional characteristics are real teaching, normal classroom teaching, focuses on training for the accomplishment of specific tasks, allows for the increased control of practice and expands the knowledge of results of feedback dimension in teaching. Lakshmi states principles of microteaching learning, they are:

1. Principe of practice, practice make a man perfect, if activity is repeatedly it is learnt effectively. Microteaching provides such practice in each small task of skill for the pupil-teacher to gain mastery over the practicing skill.

2. Principle of reinforcement, since long the value of reinforcement in the learning process has been acknowledged. In involves teacher encouraging pupil responses, using verbal praise, accepting their responses or non-verbal ones like a smile. In microteaching lesson, reinforcement encouragement is given to the student teacher from time to time for his better performance with feedback, as well as he attains satisfaction and his performance is improved. Reinforcement and feedback stimulate him to better learning and better teaching.

3. Principe of experimentation, microteaching is born in an experiment. Experiment consists of objective observation of action performed under control condition. Therefore, controlled conditions are necessary in microteaching. The student teacher and supervisors conduct experiment of teaching skill under controlled conditions. Variables such as time, content, students, and teaching techniques may be manipulated or controlled.

4. Principe of Evaluation, a proper evaluation of student teachers' work many become an effective motivation for better learning and better teaching. The supervisors evaluate each micro-lesson. In microteaching, self-evaluation is also allowed. With the help of videotape recorded, the student may evaluate his own performance. Improvement can be made on the basic of self-evaluation.

5. Principe of Precise Supervision, the supervision accompanying microteaching is highly specific and precise. The supervisors pay full attention to one point at a time. Both the supervisors and student teacher are clear about the aim of microlesson ahead of time. The supervisor processes an observation schedule that he fills in while supervising. He can also make an assessment on a rating scale, as rating is a method in which the expression or opinion concerning a particular trait is systematized.

6. Principe of Continuity, microteaching requires continuity. The student teacher learns and re-learns the skill of teaching in continuum until he masters it [9].
Shivpal Singh states the principles underlying the concept of microteaching.

1. Learner's ability becomes a consideration when determining what material taught. In this principle, the trainee is given the opportunity to choose the most mastered materials so that s/he feels comfortable with teaching them.

2. Learners are intrinsically motivated. In line with the principle, this intrinsic motivation in the context of microteaching is created through cognitive differences and effectiveness among the ideas, teacher self-concept, and actual teaching.

3. Objectives are set realistically, microteaching is implemented to practice skills that can be learned along with the expectation of learners.

4. there is only one skill trained in one microteaching activity. Students practice only one teaching skill in each microteaching session.

5. Active participation of learners is highly required to master the substance of a skill. In every microteaching situation, learners are actively involved in practicing the skills being studied.

6. Information about the trainee's appearance is highly useful for the learners themselves. Microteaching will work better if the learners get feedback related to their performance in teaching. In this case, it requires an advisor with or without video recording.

7. Feedback is given directly so that errors of learning can be well improved and this can eliminate the learner' chance of making or doing the same mistakes.

8. Training of teaching skill is done periodically. In microteaching, learners are given the experience of practicing different types of skills over period of time [11].

Taking into consideration of the expert perspectives above, the writer concludes that the principles considered in implementing the microteaching learning is that the existence of the intensive and sustainable practices, providing reinforcement, feedback, motivation, experimental activities or trials and error experiments, controlled activities of learning, evaluation towards the one's performance, balance in providing feedback, mastery, and active learner.

Wight Allen describes the implementation of microteaching done through seven stages. The six stages of microteaching form a cycle and they can be repeated in accordance with meeting the needs for improvement. The followings are the steps of microteaching learning.

1. Planning a micro-lesson determines the right subject matter that maximizes the practice of teaching skills within 5 to 7 minutes.

2. The teaching session is a lesson plan implemented in front of mentors or classmates. The performance of teachers who practice teaching skills is observed and recorded. The evaluation sheets, tape recorders, and/or video tapes can be used for such purposes. 
3. The critique session is the lecturer and the participants discuss the performance of the trainees. Feedback and key points are communicated to the trainees for selfimprovement. Evaluation tools provide an opportunity for micro teachers to view their performance objectively. The micro-participants are not given the opportunity to question for selfdefence. This is the strength and uniqueness of microteaching

4. The re-planning session is a micro participant develops a teaching plan based on the feedback offered in the critique session. The time provided for this stage is 5 to 7 minutes

5. The re-teaching session is a step to provide the opportunity for micro participants to teach the same unit and skills. Nevertheless, of course, the performance of the micro-teacher, in this session, should have paid attention to the mentors and/or peers' feedbacks. In this session, supervisors and peers evaluate the performance of the participants who perform using the observation sheet.

6. The re-critique session is the same procedure adopted as mentioned in the critique session. The micro participant gets feedback and knows how far the improvement is. This step has the potential to motivate micro participants to improve their appearance in the future [5].

\section{CONCLUSION}

In respond to the force driving ICT and the difficulty in microteaching learning process, the learning model, which adopts the ICT development into microteaching learning process, is considered as a practical and effective solution to microteaching's problem or difficult situation. This is a way of dealing with it so that the difficulty is removed. Tadaluring Microteaching Learning Model (TMLM) emphasizes on learning process optimizing classroom, online and offline practice by each participant using some kinds of ICT facilities. Tadaluring Microteaching Learning Model (TMLM) was stated valid, effective and practice in using.

\section{REFERENCES}

[1] Allen, D., and Ryan, K. 1969. Microteaching. Massachusetts Menlo Park, California: AddisonWesley Publishing Company Inc.

[2] Barmawi, \& Arifin, M. 2015. Microteaching: Teori Praktik Pengajaran yang Efektif \& Kreatif. Jogjakarta: Ar-Ruzz Media.

[3] Cooper, H. 1992. The Teaching of History Implementing The National Curriculum. London: Davis Fulton Publishers.

[4] Emzi. 2008. Metodologi Penelitian Pendidikan. Jakarta: PT Raja Grafindo Persada.

[5] Gall, J., Borg. W., \& Gall, M. 2003. Educational research: An introduction. Boston: Pearson Education.

[6] HDI. 2008. List of countries by Human Development Index. Retrieved December 9, 2016, from http://en.wikipedia.org/wiki/List_of_countries_by_ Human_Development_Index.

[7] Lakshmi, M. J. 2009. Microteaching and Prospective Teachers. New Delhi: Discovery Publishing House.
[8] Martin, Michael, O., and Mullis. 2008. TIMSS 2007: International Science Report. Chestnut Hill, MA: Boston College.

[9] Martin, Xavier, and Sala. 2008. The Competitiveness Index: Measuring the Productive Potential of Nations. In The Global Competitiveness Report 2008-2009.

[10] Singh, L. C. 1979. Microteaching: An Innovation in Teacher Education. New Delhi: NCERT.

[11] Sukirman, D. 2012. Pembelajaran Microteaching, Jakarta: Direktorat Pendidikan Agama Islam, Kementerian Agama. 